\title{
AVALIAÇÃO DA GERMINAÇÃO EM SEMENTES DE SOJA SUBMETIDAS A DIFERENTES
} PERÍODOS DE EMBEBIÇÃO

\author{
André Bin, Cleberson Alves Brandão, Marcelo Vigolo, Nadielli Zanini Andrade, Luciana de Oliveira \\ Derré \\ Faculdade Centro Mato-Grossense, Curso de Agronomia, Cidade Sorriso, Estado Mato Grosso. Email: \\ nadiellizaandrade@gmail.com
}

\begin{abstract}
RESUMO
A primeira etapa para o desenvolvimento de uma planta é absorção de água pela semente, desencadeando uma série de processos metabólicos que afetam a germinação e consequentemente todo o seu desenvolvimento. $\mathrm{O}$ objetivo deste estudo foi avaliar a absorção de água pela semente de soja e seus danos sobre a germinação e desenvolvimento inicial da plântula, quando embebida em água, durante diferentes períodos de tempo. A metodologia constou de seis tratamentos, sendo estes períodos de tempo de embebição de $0 ; 6 ; 12 ; 24 ; 36 ; 48$ e 60 horas. Após esse período foi realizado o teste de germinação, avaliando o desenvolvimento de plântulas e raiz. A média dos resultados foi analisada pelo teste de Tukey a $5 \%$ de probabilidade, através do programa SISVAR. Os resultados não indicaram que houve um decréscimo no índice de germinação e o número de plântulas anormais aumentou com o passar do tempo de embebição. Conclui-se que quanto maior o período de embebição, maiores são os danos.

Palavras-chave: Soja, Danos, Embebição, Germinação, Glycine max.
\end{abstract}

\section{EVALUATION Of GERMINATION IN SOYBEANS UNDER DIFFERENT SOAKING TIME}

\begin{abstract}
The first step of the development of a plant is the water absorption by the seed, which leads to a cascade of metabolical processes that afect germination and the future. The objective of this work was to evaluate the water absorption by the soybean seed and its effects, in the initial development of the seedlings, when imbibed in water for different periods. The experiment was composed by six treatments (imbibition times) of $0 ; 6 ; 12 ; 24 ; 36 ; 48$ and 60 hours. After that the germination test was applied and the development of the seedlings evaluated. The results were evaluated by the Tukey's test $(p<0.05)$ by the SISVAR software. Results showed not that a decrease in the germination and an increase in the abnormal seedlings occurred with the increase in the imbibition time. So, as long is the imbibition the bigger is the damage for soybean seedlings.
\end{abstract}

Keywords: Soy, Damages, Soaking, Germination, Glycine max. 


\section{INTRODUÇÃO}

A primeira etapa para o desenvolvimento de uma planta começa pela absorção de água pela semente, desencadeando uma série de processos metabólicos relacionados à germinação da mesma e consequentemente ao seu desenvolvimento como um todo.

Segundo Toledo (2008), durante a germinação de uma semente ocorre a reativação do crescimento do embrião, o que acarreta na ruptura da cobertura da semente e na emergência da plântula. Ou seja, a semente interrompe o seu desenvolvimento quando se desliga da planta mãe, a reativação de seu desenvolvimento ocorrerá quando houver condições ambientais favoráveis para isso.

O processo de germinação, portanto, irá depender de diversos fatores, entre eles a quantidade de água presente no solo e a velocidade de absorção da mesma. Desta maneira, quando a semente é semeada no solo, ela já está bastante desidratada para evitar que ocorra a germinação em ambientes desfavoráveis. Contudo, ao entrar em contato com o solo e com a umidade do mesmo, a semente passa a absorver água rapidamente para iniciar todo o seu metabolismo (TOLEDO, 2008).

Esse processo de absorção pode ser mais lento, com uma quantidade de água absorvida mais uniforme, e pode ser mais acelerado; gerando uma absorção em maior quantidade, podendo afetar o seu desenvolvimento, devido a danos causados em suas membranas.

Sementes com maior teor de amido tem tendência a absorver água mais rapidamente, devido a sua capacidade hidrofílica. Com isso a porcentagem e a qualidade da germinação da semente de soja podem ser afetadas pelo processo de embebição, caso esse ocorra de maneira acelerada (MARCOS FILHO, 2005).

O objetivo deste estudo foi avaliar a absorção de água pela semente de soja durante diferentes períodos de tempo de embebição e seus efeitos quanto à germinação e desenvolvimento inicial de plântulas.

\section{METODOLOGIA}

O trabalho foi conduzido no laboratório da Faculdade Centro Mato-Grossense em Sorriso (MT), no mês de maio. Utilizou-se neste experimento sementes de um lote de soja (Glycine max) cultivar GB 874, da safra 2014/2015.

O umedecimento foi composto por períodos de embebição (tratamentos) de 0 , 6; 12; 24; 36; 48 e 60 horas, compondo-se quatro repetições por período de embebição. Para tanto, as 
sementes foram embebidas em água destilada sobre placas de petri e papel germitest, utilizandose para cada período 50 sementes por repetição.

Durante o processo de embebição, a semente permaneceu no escuro, com temperatura média de $25^{\circ} \mathrm{C}$, nos períodos já citados anteriormente. A quantidade de água destilada utilizada para manter a embebição equivale a 2,5 vezes peso massa do papel seco, sendo essa quantidade igual a 7,5 $\mathrm{ml}$ de água destilada/placa de petri que foi reposta a cada 12 horas, para manter o processo de embebição durante o período de tempo de cada tratamento.

Decorrido este período de incubação no escuro, as sementes foram submetidas ao teste de germinação, segundo as Regras de Análise de Sementes (RAS) (Brasil, 2009). A quantidade de água destilada utilizada na instalação do teste de germinação a embeber as sementes foi determinada através do peso correspondente a 2,5 vezes a massa do papel não hidratado. As contagens de germinação foram realizadas no quinto dia no início do teste.

Para avaliação da germinação, foram consideradas germinadas aquelas sementes que apresentaram raiz primária com comprimento igual ou superior a $0,5 \mathrm{~cm}$ e plântula com comprimento igual ou superior a $1,0 \mathrm{~cm}$. Atendendo essas especificações, as sementes germinadas foram mensuradas quanto ao comprimento da parte aérea $(\mathrm{cm})$ e ao comprimento da raiz primária $(\mathrm{cm})$, assim como também foram determinadas as contagens das sementes que apresentaram fungos e das sementes não germinadas.

A avaliação do crescimento de plântulas foi realizada de acordo com Nakagawa (1999), sendo que para essa avaliação foram distribuídas dez sementes sobre uma linha mediana traçada no sentido longitudinal do papel substrato pré-umedecido. Confeccionaram-se rolos semelhantes ao teste de germinação, gerando a mesma quantidade de tratamentos e repetições. Após o preparo dos rolos, estes foram levados ao germinador durante cinco dias, seguindo-se o procedimento descrito para o teste de germinação. Das plântulas normais obtidas avaliou-se o comprimento do hipocótilo e da raiz primária.

O delineamento experimental utilizado foi o inteiramente casualisado com quatro repetições. Para a análise de variância aplicou-se o teste $F$, e quando este foi significativo, a comparação de médias foi realizada através do teste Tukey a 5\% de probabilidade, utilizando o software SISVAR (Ferreira, 2011).

\section{RESULTADOS}

Na Figura 1 não foi possível observar diferenças significativas entre os períodos de embebição, não podendo ser constatada a interferência da embebição sobre a germinação. 
\% de Germinação e Anormalidades X Períodos de Embebição

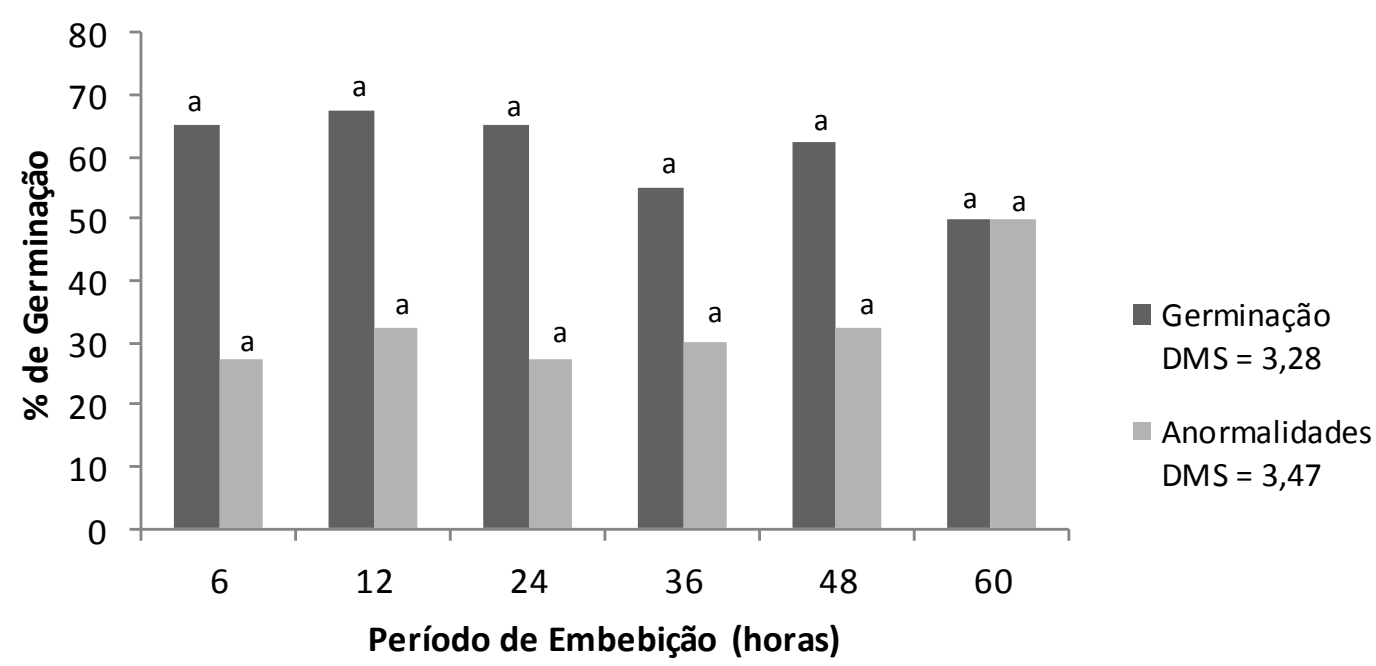

Figura 1. Gráfico de germinação e anormalidades para cada período de tempo.

A incidência de plântulas anormais não foi afetada significativamente pelo aumento da exposição das sementes aos períodos de embebição. Foi verificado que a incidência de plântulas anormais aumentava correspondendo ao incremento do tempo de embebição. Nos períodos de 6 horas até de 60 horas, a porcentagem de plântulas anormais foi de 27,5 para 50\%, respectivamente, entretanto suas diferenças não demonstraram ser significativas.

Na Figura 2, observa-se o desajuste de desenvolvimento de parte aérea e raiz entre os tempos de embebição 12 e 24 horas. Tais períodos apresentaram diferenças significativas, uma vez que os períodos 12 e 24 horas obtiveram desempenho inferior ao período de seis horas, com diferenças médias de 3 a $4 \mathrm{~cm}$. Os demais períodos de embebição não apresentaram diferenças significativas.

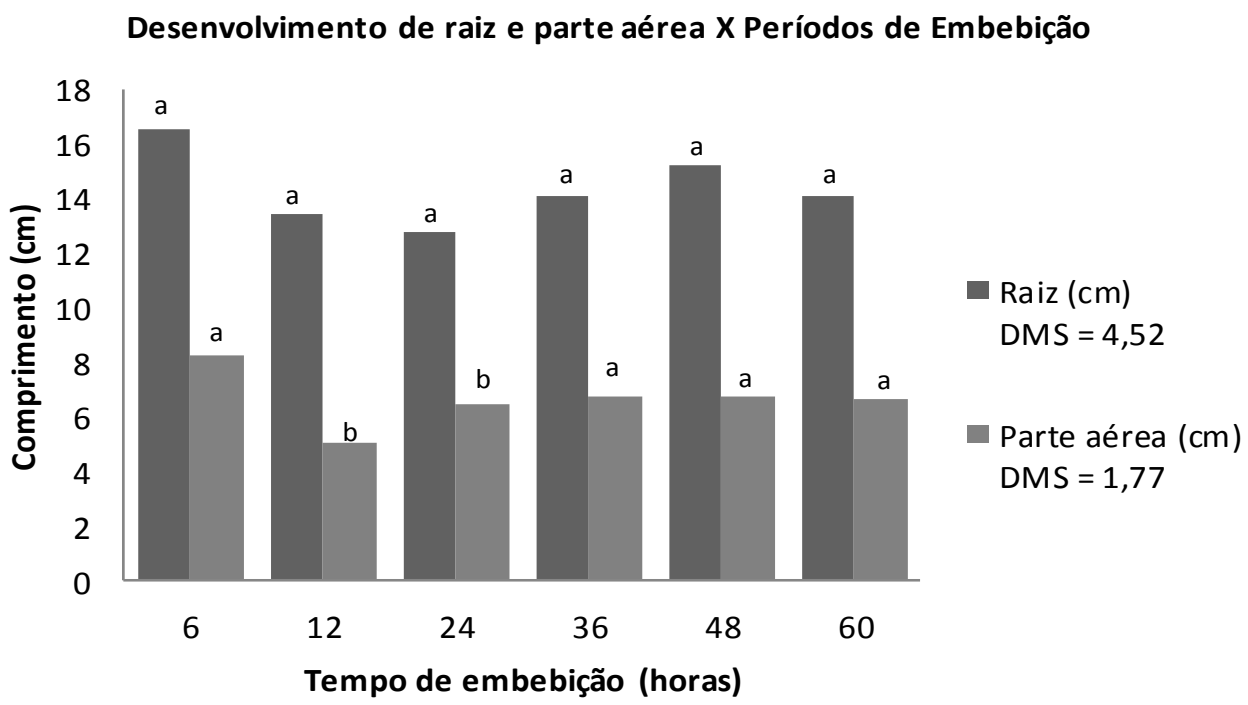

Figura 2. Gráfico de comprimento de parte aérea e raiz para cada tratamento. 


\section{DISCUSSÃO}

Através dos dados de germinação não foi possível verificar a influência do período de embebição sobre as sementes, sendo este o primeiro momento do processo de germinação. Destacando que, este processo pode resultar em danos à semente caso esta esteja muito seca e o substrato (solo ou germitest) com excesso de umidade (PESKE 2011). Fato este observado neste experimento pelo decréscimo da germinação da soja conforme houve aumento do período de embebição da semente.

Segundo Peske (2011), os danos relativos à embebição podem ser atribuídos à ruptura das membranas celulares das sementes, ocasionada pela intensa entrada de água nos primeiros momentos de embebição, devido à diferença de potencial hídrico entre a semente e o substrato onde ela se localiza.

Situação semelhante é exposta por Castro e Hilhorst (2004), os quais destacam que o dano por embebição ocorre quando as sementes são expostas à rápida absorção de água, não permitindo a completa reestruturação do sistema de membranas celulares, ocasionando a lixiviação de conteúdos celulares e resultando em prejuízos ao desempenho das sementes durante as fases subsequentes da germinação.

Monteiro et al. (2014), avaliando diferentes cultivares de soja (BMX Titan RR, CD 226 RR, RA 626, FPS Netuno RR e BMX Energia RR) em variados períodos (2; 4; 6; 8 e 10 horas) de submersão em água, observaram que duas horas de embebição já foram suficientes para causar redução significativa na germinação. Segundo estes autores, a germinação das sementes de todas as cultivares avaliadas decresceu linearmente com o aumento do período de submersão (MONTEIRO et al., 2014).

O desenvolvimento de parte aérea e comprimento de raiz de plântulas oriundas de sementes expostas à embebição demonstraram sofrer influência significativa reduzindo seus valores em até $1,5 \%$ quando em período de 12 e 24 horas, colaborando com as afirmações de Peske (2011) onde destaca a importância em se conhecer as condições em que as sementes serão expostas a fim de que estas não incidam negativamente no seu desenvolvimento, pois a partir do momento que a embebição dar início ao processo germinativo, através da água absorvida pela semente, esta deixa de ser um organismo em repouso para começar o processo de desenvolvimento embrionário e, por conseguinte desta etapa originar o desenvolvimento de plântula normal, adulta e completamente desenvolvida. 


\section{CONCLUSÃO}

Concluiu-se que não houve interferência entre dos períodos de embebição sobre a quantidade de sementes de soja germinadas ou anormais, entretanto os períodos de 12 a 24 horas de embebição podem afetar o desenvolvimento de parte aérea e raiz de plântulas de soja exposta a estes respectivos períodos de embebição.

\section{REFERÊNCIAS}

BRASIL. Ministério da Agricultura, Pecuária e Abastecimento. Regras para análise de sementes. Ministério da Agricultura, Pecuária e Abastecimento. Secretaria de Defesa Agropecuária. Brasília, DF: Mapa/ACS, P.395. 2009

CASTRO, R.D.; HILHORST, H.W.M. Embebição e reativação do metabolismo. In: FERREIRA, A.G.; BORGHETTI, F. Germinação: do básico ao aplicado. Porto Alegre, Artmed, P.149-162. 2004.

MARCOS FILHO, J. M.; Fisiologia de sementes de plantas cultivadas. 1. ed. P. 495. v.12. 2005

MONTEIRO, M. A.; MARTINS, A. B. N.; VÉRA, J.G.; MEDEIROS, L. R. DE; COSTA, C.J.; Efeitos de diferentes períodos de submersão em água na germinação de sementes de soja. 12a Jornada de Pós-Graduação e Pesquisa. Revista Congrega Ercamp. P. 1 - 12, 2014.

NAKAGAWA, J. Testes de vigor baseados no desempenho das plântulas. In: KRZYZANOSKI, F.C.; VIEIRA, R.D.; FRANÇA NETO, J.B. (Ed.). Vigor de sementes: conceitos e testes. Londrina: ABRATES, P.2.1-2.24. 1999.

TOLEDO, M. Z.; Dano por embebição em sementes de soja em função do teor de água inicial, cultivar e local de produção. 2008. Dissertação (Mestrado em Agronomia) - Faculdade de ciências Agronômicas, Universidade Estadual Paulista “Julio de Mesquita Filho", Botucatu, 2008.

PESKE, S. T.; PESKE, F. B; Absorção de água sob estresse. Seed News. n.3, 2011. Disponível em: <http://www.seednews.inf.br>. Acesso em: 20 março de 2015. 